\title{
Progress in the classical biological control of Agrilus planipennis Fairmaire (Coleoptera: Buprestidae) in North America-CORRIGENDUM
}

\author{
Leah S. Bauer, Jian J. Duan, Juli R. Gould, Roy Van Driesche
}

doi:10.4039/tce.2015.18, published by Cambridge University Press, 12 May 2015

Authority to release classical biological control agents for management of the emerald ash borer (EAB), Agrilus planipennis Fairmare (Coleoptera: Buprestidae), was granted by the United States Department of Agriculture, Animal and Plant Health Inspection Service (APHIS) in the United States of America and the Canadian Food Inspection Agency (CFIA) in Canada, not the North American Plant Protection Organization (NAPPO) as suggested on pages 307, 308, and 309 (Bauer et al. 2015). The NAPPO biological control panel, with members from Canada, Mexico, and the United States of America, developed regional standards for insect biocontrol agents that are similar to those developed by the International Plant Protection Convention of the Food and Agriculture Organization (FAO) of the United Nations (Mason et al. 2013). The NAPPO standards for non-indigenous entomophagous biocontrol agents are described in the regional standards for phytosanitary measures (RSPM) number 12 (North American Plant Protection Organization 2008). Currently, petitions for the release of entomophagous biocontrol agents in North America are reviewed by the biological control review committee (BCRC) following the standards outlined in RSPM number 12. The BCRC, which includes members from Canada, Mexico, and the United States of America and is coordinated by Agriculture and Agri-Food Canada, provides scientific evaluation of petitions and makes release recommendations to both APHIS and CFIA (Montgomery 2011).

\section{References}

Bauer, L.S., Duan, J.J., Gould, J.G., and Van Driesche, R.G. 2015. Progress in the classical biological control of Agrilus planipennis Fairmaire (Coleoptera: Buprestidae) in North America. The Canadian Entomologist, 147: 300-317. doi:10.4039/tce.2015.18.

Mason, P.G., Kabaluk, J.T., Spence, B., and Gillespie, D.R. 2013. Regulation of biological control in Canada. In Biological control programmes in Canada 2001-2012. Edited by P.G. Mason and D.R. Gillespie. CABI Publishing, Wallingford, Oxon, United Kingdom. pp. 1-5.

Montgomery, M. 2011. Understanding federal regulations as guidelines for classical biological control programs. In Implementation and status of biological control of the hemlock woolly adelgid. Edited by B. Onken and R. Reardon. FHTET-2011-04. United States Department of Agriculture, Forest Service, Morgantown, West Virginia, United States of America. pp. 25-40. Available from http://www.fs. fed.us/nrs/pubs/jrnl/2011/nrs_2011_montgomery_001. pdf [accessed 4 August 2015].

North American Plant Protection Organization. 2008. Regional standards for phytosanitary measures (RSPM) 12: guidelines for petition for first release of nonindigenous entomophagous biological control agents. Available from http://www.nappo.org/en/data/files/ download/PDF/Introduction\%20to\%20NAPPO-April\% 202011-e.pdf [accessed 4 August 2015]. 